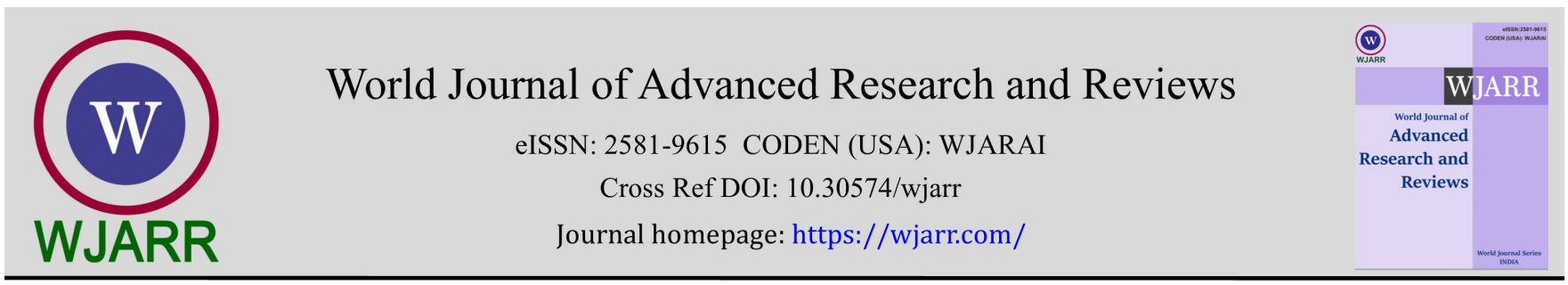

(RESEARCh ARTICLE)

Check for updates

\title{
Is there any correlation between Magnesium status and depression in elderly people? A descriptive-analytical study among Tehran-nursing home residents
}

Lyly Nazemi 1,2,3, Ingmar Skoog 4, Ingvar Karlsson 4, Margda Waern 4, Agneta Yngve 5,6, Gunnar Akner 7, Alireza Mesbah Namin 8, Azam Afshar Naderi 8, Shahram Pour Byranvand ${ }^{9}$ and Zahra Farahani 1,*

${ }^{1}$ Maternal, Fetal, and Neonatal Research Center, Tehran University of Medical Sciences, Tehran, Iran.

${ }^{2}$ Department of Clinical Nutrition, Faculty of Nutritional Science and Dietetic, Tehran University of Medical Sciences,

Tehran, Iran.

${ }^{3}$ Breastfeeding Research Center, Tehran University of Medical Sciences, Tehran, Iran.

${ }^{4}$ Department of Psychiatry and Neurochemistry, Neuropsychiatric Epidemiology Unit, Institute of Neuroscience and Physiology, Sahlgrenska Academy, University of Gothenburg, Sweden.

${ }^{5}$ Department of Biosciences and Nutrition, NOVUM, Karolinska Institute, Sweden.

${ }^{6}$ Department of food, nutrition and dietetics, Uppsala University Sweden.

${ }^{7}$ Department of Neurobiology, Care Sciences, and Society-NVS, Karolinska Institute, Sweden.

${ }^{8}$ Department of Clinical Biochemistry, Tarbiat Modares University, Tehran, Iran.

${ }^{9}$ Department of Anatomical Sciences, Tarbiyat Modares, University, Tehran, Iran.

World Journal of Advanced Research and Reviews, 2021, 12(02), 632-639

Publication history: Received on 21 October 2021; revised on 28 November 2021; accepted on 30 November 2021

Article DOI: https://doi.org/10.30574/wjarr.2021.12.2.0646

\begin{abstract}
Background: Very few studies have shown the possible relationship between magnesium (Mg) status and depression. In the present study, the intracellular Mg status of the elderly population living in nursing homes (NHs) was assessed to determine its relationship with depression.
\end{abstract}

Methods: A descriptive-analytical study was conducted on the elderly population living in nursing homes (Tehran-Iran; 2010-2012). Participants' demographic and clinical characteristics were collected and recorded in a checklist. Evaluating the participants' nutritional status, Mini Nutritional Assessment Method was implemented. Determining participant's depressive symptoms, 15-item Geriatric Depression Scale was used. Final scores were classified into4 categories not depressed, mild, moderate, and severe depression. Mg level in leukocytes was also measured by flame atomic absorption spectrometry.

Results: Totally 113 elderly were included and only $9.8 \%$ of subjects were not depressed. About $21 \%$ of the subjects were well nourished. Of participants who suffered from heart disease, $80.2 \%$ were depressed $(p=0.03)$. Regarding correlations between Mg status and depression, results showed no significant difference in Mg levels of two depressed and non-depressed participants $(\mathrm{p}=0.73)$.

Conclusion: The results of the present study showed notable prevalence rates of depression and malnutrition among nursing home residents. It was also found that the relationship between intracellular Mg levels and depression was not significant. Further studies are needed to determine the major factors related to these preventable psychological and nutritional disorders among elderly $\mathrm{NH}$ residents.

Keywords: Magnesium; Depression; Elderly; Nursing home

\footnotetext{
* Corresponding author: Zahra Farahani

Maternal, Fetal, and Neonatal Research Center, Tehran University of Medical Sciences, Tehran, Iran.

Copyright $(2021$ Author(s) retain the copyright of this article. This article is published under the terms of the Creative Commons Attribution Liscense 4.0.
} 


\section{Introduction}

Magnesium (Mg) as the second predominant intracellular cation plays crucial roles in enzymatic reactions (as a cofactor) and neuronal function (as a calcium antagonist)[1]. The relationships between $\mathrm{Mg}$ with both specific and nonspecific immune responses were also well defined[2]. There are a large number of data showing the correlations between magnesium deficiency with different complications including cardiovascular diseases, osteoporosis, diabetes mellitus, and mental disorders [3-5].

The link between aging and Mg deficiency has also been shown. Insufficient intake, alterations in Mg metabolism, and age-related chronic disease are factors that may affect Mg status in the old-age population [2]. It was reported that in the elderly, chronic Mg insufficiency may deteriorate the risks of depression and other neuropsychiatric disorders [6, 7].

Depression is the main cause of disability with an increased advent in old age [8, 9]. Based on the WHO (World Health Organization) report, $7 \%$ of old adults (age $>65$ years old) are prone to depression. The prevalence of major depression was reported 1-16\% among elderly living in private households or in nursing homes [10].

Although there are diversities in the available data showing the link between $\mathrm{Mg}$ concentration and mental disorders [11], Andrasi et al. reported a positive correlation between Mg deficiency and the severity of depression symptoms. They showed that Mg intake could improve the clinical symptoms [12]. Jacka et al. also demonstrated Mg deficiency in patients with depressive illness [13].

Magnesium accompanied by calcium is usually found in hard water. A high-fiber diet also is a rich Mg source. While today the wide use of soft water and refined flour may expose the population to great risk for Mg deficiency [14]. Up to our knowledge, very little data are existent about the relationship between Mg status and depression. As a small fraction of total body magnesium is detected in the blood (1\% in blood and 99\% in intracellular space)[15], the blood or urine analyses may not be an appropriate method assessing of Mg levels. Recently, measuring Mg concentration in the erythrocyte or leukocyte has provided a valuable index indicating intracellular magnesium status [16]. This difficulty may explain why so little is known about the correlation between magnesium and different disorders. Herein, by the present survey, we aimed to assess the intracellular Mg status of the elderly population living in the nursing homes (NHs) to determine the possible relationship between Mg levels and depression. Understanding the influential factors can propose a practical solution for the prevention of this disorder.

\section{Material and methods}

A descriptive-analytical study was conducted in the School of Public Health (affiliated with Tehran University of Medical Sciences) in cooperation with the National Health Research Association, and the National Institute of Health Research (Tehran-Iran) in 2010-2012.

Of totally 44 public and private nursing homes (with 2500 elderly residents) in Tehran, 17 nursing homes (geographically scattered in Tehran) were randomly selected and 113 eligible subjects entered in the study. Inclusion criteria were the age of 60 years or above and living in the nursing home. Deaths of individuals or unwillingness for cooperation were considered as exclusion criteria were. After signing of informed consent and entering the study, participants' demographic and clinical characteristics including age, sex, history of chronic disease (diabetes, hypertension, renal or heart disease), exposure to sunlight, dental health status, the levels of satisfaction regarding food quality, and personnel in nursing homes were collected and recorded in a checklist. Evaluating the participant's nutritional status, Mini Nutritional Assessment Method (MNA) was implemented. Determining participants' depressive symptoms in the elderly population, a 15-item Geriatric Depression Scale (GDS) with a high level of internal consistency (Cronbach's alpha $=0.80$ ), reliability, and validity was used $[17,18]$. The GDS is composed of 15 Yes-No items showing the presence of depression [19, 20]. Final scores were classified in 4 categories; 0-4, 5-8, 9-11, and 12-15 suggesting not depressed, mild, moderate, and severe depression, respectively [21, 22].

In order to measure the Mg levels in leukocytes, 5 milliliters of fasting venous blood were drowned in a heparinized tube. After adding $5 \mathrm{ml}$ of PBS, the content was gently transferred to another tube containing $3 \mathrm{ml}$ of Ficoll- Hypaque (0771/1 Sigma Aldrich, Germany). Then, the tube was centrifuged at $400 \mathrm{RPM}$ for 15 minutes at $4^{\circ} \mathrm{C}$. After centrifuge, 4 layers were formed that the lowest layer contained the red blood cells. The second, third, and the upmost layers were the Ficoll, mononuclear cells (a cloudy layer), and plasma, respectively. With a pipette, the cloudy and plasma layers were removed, washed with PBS, and centrifuged at $300 \mathrm{RPM}$ for 5 minutes at $20^{\circ} \mathrm{C}$. The perimeter was evacuated and 
the procedure was repeated. Leukocytes were lysed by sonication in $10 \mathrm{mmol} / \mathrm{L}$ of $\mathrm{NaCl}$ and the Mg in the cell lysate (with adding $2.93 \mathrm{~g}$ of lanthanum oxide per liter) was detected by flame atomic absorption spectrometry (FAAS). The low, medium, and high ranges for intracellular $\mathrm{Mg}$ concentration were considered as $<3.9,3.9-10.0$, and $>10.0$ nmol/106ell, respectively [23].

The study was confirmed by the Medical Ethics Committee of Tehran University of Medical Sciences (ID: 4656).

\subsection{Statistical Analysis}

Data were analyzed using SPSS software (17.0) and STATA (11.0). Univariate and multivariate ordinal polytomous regression were employed to investigate the association between malnutrition and its risk factors. As the nursing homes formed a cluster in our sampling scheme, Complex Sample Survey (SVY) ordinal regression analysis was performed in STATA to account for the data structure. The frequency, type, and direction of the relationship between variables and the relative distance were determined using the Pearson correlation coefficient. The relationship between independent categorical variables was evaluated by the Chi-square test. Qualitative data was analyzed through the Fisher test. A Pvalue of less than 0.05 was considered significant.

\section{Results}

Totally 113 elderlies (53.3\%; female and 46.7\%; male) were included. The mean ( \pm SD) age of participants was 75.8 ( \pm 8.7 ) years. Of all, only $9.8 \%$ of subjects were not depressed, while $50.0 \%, 29.5 \%$, and $10.7 \%$ had mild, moderate, and severe depression, respectively. Sixteen percent had diabetes, $23.1 \%$ hypertension, 3.8\% renal disease, and $5 \%$ digestive problems. Of participants who suffered from heart disease, $80.2 \%$ were depressed ( $\mathrm{p}=0.03$ ). Regarding $\mathrm{Mg}$ status, 37 (32.74\%), 39 (34.52\%), and 37 cases (32.74\%) showed low, moderate, and high levels of leukocytes Mg, respectively. Only20.9\% of the subjects were well nourished and the others were malnourished or at risk of malnutrition. Consuming vitamin or mineral supplements was reported in $3.7 \%$ of subjects. Regarding dental health, $27.2 \%$ had no teeth or dentures.

Measuring intracellular status by FAAS method showed that 37 (32.74\%) of the elderly population had low a level, 39 (34.52\%) medium level, and 37 (32.74\%) high level of intracellular Mg. Of all participants, 34.55\% of male and 31.03\% of female subjects showed high levels of $\mathrm{Mg}$. The low level of $\mathrm{Mg}$ was less frequent among older participants. $\mathrm{NH}$ residents with higher education showed a higher level of Mg. Cases with malnutrition or those who did not receive supplements had high ranges of Mg. Demographic characteristics and magnesium status among participants are presented in Table 1.

Table 1 Demographic characteristics and magnesium status among participants

\begin{tabular}{|c|c|c|c|}
\hline $\begin{array}{l}\text { Magnesium } \\
\text { Variables }\end{array}$ & $\begin{array}{l}<3.9 \\
\text { nmol/106cell } \\
\text { (percent) }\end{array}$ & $\begin{array}{l}\text { 3.9-10.0 nmol } / 10^{6} \text { cell } \\
\text { (percent) }\end{array}$ & $\begin{array}{l}>10.0 \mathrm{nmol} / 10^{6} \mathrm{cell} \\
\text { (percent) }\end{array}$ \\
\hline \multicolumn{4}{|l|}{ Gender } \\
\hline Male & 32.73 & 32.73 & 34.55 \\
\hline Female & 32.76 & 36.21 & 31.03 \\
\hline \multicolumn{4}{|l|}{ Age groups (years) } \\
\hline $60-74$ & 35.42 & 31.25 & 33.33 \\
\hline $75-85$ & 35.56 & 33.33 & 31.11 \\
\hline Older & 20 & 45 & 35 \\
\hline \multicolumn{4}{|l|}{ Education } \\
\hline Illiterate & 36.96 & 39.13 & 23.91 \\
\hline Lower diploma & 32.26 & 38.71 & 29.03 \\
\hline Diploma and higher & 28 & 32 & 40 \\
\hline \multicolumn{4}{|l|}{ Nutritional status } \\
\hline Well-nourished & 52.63 & 15.79 & 31.58 \\
\hline
\end{tabular}




\begin{tabular}{|l|l|l|c|}
\hline At the risk of malnutrition & 30.23 & 38.37 & 31.40 \\
\hline Malnutrition & 12.50 & 37.50 & 50 \\
\hline Taking supplements & 42.86 & 57.14 & 0 \\
\hline Yes & 32.38 & 33.33 & 34.29 \\
\hline No &
\end{tabular}

Regarding correlations between Mg status and depression, results showed that the majority of non-depressed subjects (81.9\%) had low to moderated Mg concentrations. While $68.5 \%$ of cases with mild, $73.3 \%$ with moderate, and $57.2 \%$ with severe depression showed low and moderate Mg levels. Furthermore, a high level of Mg was detected in only $18.2 \%$ of non-depressed cases. On the other hand, larger numbers of depressed cases showed high levels of Mg in comparison with non-depressed subjects $(31.5 \%, 26.7 \%$, and $42.9 \%$ of cases with mild, moderate, and severe depression, respectively). However, these differences were not significant between two depressed and non-depressed participants $(\mathrm{p}=0.73)$ (Table 2).

Table 2 Correlations between Magnesium levels with diabetes, hypertension, heart disease, renal disease, dental health, the satisfaction of food quality, the satisfaction of personal, sunlight exposure, and depression

\begin{tabular}{|c|c|c|c|c|c|}
\hline \multicolumn{2}{|l|}{$\begin{array}{l}\text { Magnesium } \\
\text { Variables }\end{array}$} & $\begin{array}{l}<3.9 \\
\text { nmol } / 10^{6} \text { cell } \\
\text { (percent) } \\
\end{array}$ & $\begin{array}{l}3.9-10.0 \\
\text { nmol/106cell } \\
\text { (percent) }\end{array}$ & $\begin{array}{l}>10.0 \\
\text { nmol } / 10^{6} \text { cell } \\
\text { (percent) } \\
\end{array}$ & P value \\
\hline \multirow{4}{*}{ Depression } & No & 36.4 & 45.5 & 18.2 & \multirow{4}{*}{0.73} \\
\hline & Mild & 29.6 & 38.9 & 31.5 & \\
\hline & Moderate & 43.3 & 30 & 26.7 & \\
\hline & Severe & 14.3 & 42.9 & 42.9 & \\
\hline \multirow[t]{2}{*}{ Diabetes } & Yes & 31.6 & 42.1 & 26.3 & \multirow[b]{2}{*}{0.67} \\
\hline & No & 33.0 & 33.0 & 34.0 & \\
\hline \multirow[t]{2}{*}{ Hypertension } & Yes & 28.6 & 42.9 & 28.6 & \multirow[t]{2}{*}{0.58} \\
\hline & No & 34.5 & 32.1 & 33.33 & \\
\hline \multirow[t]{2}{*}{ Heart Disease } & Yes & 22.6 & 45.2 & 32.3 & \multirow[t]{2}{*}{0.28} \\
\hline & No & 35.8 & 30.9 & 33.3 & \\
\hline \multirow[t]{2}{*}{ Renal Disease } & Yes & 0 & 0 & 100 & \multirow[t]{2}{*}{0.31} \\
\hline & No & 33.0 & 35.8 & 31.2 & \\
\hline \multirow{2}{*}{$\begin{array}{l}\text { Bad Dental } \\
\text { Health }\end{array}$} & Yes & 33.3 & 33.3 & 33.3 & \multirow[t]{2}{*}{0.21} \\
\hline & No & 32.6 & 34.9 & 32.6 & \\
\hline \multirow{2}{*}{$\begin{array}{l}\text { Satisfaction of } \\
\text { Food Quality }\end{array}$} & Yes & 34.0 & 32.0 & 34.0 & \multirow[t]{2}{*}{0.33} \\
\hline & No & 20 & 60 & 20 & \\
\hline \multirow{2}{*}{$\begin{array}{l}\text { Satisfaction of } \\
\text { Personal }\end{array}$} & Yes & 33.3 & 35.2 & 31.5 & \multirow[t]{2}{*}{0.52} \\
\hline & No & 20 & 20 & 60 & \\
\hline \multirow{3}{*}{$\begin{array}{l}\text { Sunlight } \\
\text { Exposure }\end{array}$} & No & 38.1 & 26.2 & 35.7 & \multirow{3}{*}{0.47} \\
\hline & $<2 \mathrm{~h}$ & 25.9 & 40.7 & 33.3 & \\
\hline & $2-8 \mathrm{~h}$ & 41.0 & 35.3 & 23.5 & \\
\hline
\end{tabular}

Although high Mg levels were more frequently observed among non-diabetics compared to diabetic cases, the difference was not significant (34.0\% vs. 26.3\%; $\mathrm{p}=0.67$ ). More hypertensive cases had low and moderate Mg levels compared to non-hypertensive subjects (71.43 vs. $66.66 \%$; $=0.58$ ). High levels of magnesium were observed in all participants with renal disease (100\%), while about one-third (31.2\%) of subjects without renal disease showed such a high level $(\mathrm{p}=0.31)$. No notable differences were observed between cases with and without heart diseases with respect to Mg 
levels ( $p=0.28)$. Other factors such as dental health status ( $p=0.21)$, sunlight exposure $(p=0.47)$, satisfaction of NH's staff ( $p=0.33$ ), or food quality ( $p=0.52$ ) could not significantly alter Mg levels. Finally, No significant relationship was observed between $\mathrm{Mg}$ levels and nutritional status $(\mathrm{P}=0.18)$.

\section{Discussion}

Depression among the elderly is a serious problem that may increase the rate of morbidity or mortality [24]. Previous studies have indicated that depressed old adults had poorer functioning when compared with people with other chronic complications such as cardiopulmonary disease, arthritis, or diabetes [25]. It was also reported that anti-depressant medications are not always successful and even may increase the suicide rate [26]. On the other hand, nutrition as one of the most important environmental factors could notably improve, prevent, or shorten the period of different illnesses [27]. The primary outcome of the present study was to evaluate any possible correlation between depression and intracellular magnesium status in elderly residents of selected NHs in Tehran-Iran.

According to the results, $50.0 \%$ and $40.2 \%$ of our participants showed mild and moderate to severe depression. The other studies from Iran also showed such a prevalent mental complication among the Iranian elderly [28-31]. A systematic review and meta-analysis showed depression in 43\% (CI 95\%: 30\%-55\%) of 5781 included Iranian elderly population [29]. The other investigation has shown that 52\% (CI 95\%: 46-58) of the Iranian elderly aged 64.22 to 76.97 years suffered from depression [30]. The prevalence of depression among elderly living in different cities of Iran was also reported from $0.03 \%$ (in Khoy; 2016) to $82.1 \%$ (in Koram Abad; 2013) by the other study [31]. This high prevalence of depression indicates that the screening, early diagnosis, and prevention of depression among the elderly population particularly NH residents with higher risk factors should be strongly considered.

The results also indicated a significant relationship between depression and heart disease; the majority of our participants $(80.2 \%)$ who suffered from heart disease were depressed. Chronic complications like heart disease may severely impact on quality of life that may prone elderly subjects to getting depression. In accordance with our findings, Tang et al. showed that heart disease was a significant risk factor for mental health disorders in elderly patients [32]. Al et al. also showed a positive correlation between depression and heart disease [33]. This finding shows that for preventing depression in the elderly, the overall health status of subjects should be noticed.

According to the results, unfortunately, about $80 \%$ of our participants living in NHs were malnourished or at risk of malnutrition. It is supposed that several reasons may be involved; inadequate energy/nutrients, macro, and micronutrients intakes secondary to subjects' low income, psychological and non-psychological health problems (affecting appetite, ingestion, digestion, and absorption processes), worse nutritional status, and no food choices in nursing homes are some of them. Our data were also shown that very few percent of participants (3.7\%) received vitamin or mineral supplements and $27.2 \%$ had no teeth or dentures. So it seems that public health strategies should strongly focus on nutritional interventions as well as old-aged adults' health status to improve nutritional outcomes in NHs elderly residents. These findings were confirmed by our former study that showed a notable rate of malnutrition with significant relationships with lower food intake, no teeth or good prosthesis, diabetes, smoking, studying, and praying in the free time among NH elderly residents [34]. Consistent with our finding, Madeira et al. showeda high frequency of malnutrition and inadequate protein intake among the elderly population living in $\mathrm{NH}$. The authors also demonstrated that there was a significant and inverse relationship between energy intake and malnutrition among their study population [35].

Regarding correlations between intracellular Mg status and depression, results showed that the majority of nondepressed subjects had low to moderate Mg concentrations. On the other hand, a larger number of mild to severe depressed cases (31.5\%, 26.7\%, and 42.9\%) showed high levels of Mg when compared with non-depressed subjects $(18.2 \%)$. As these differences were not significant, it seems that other significant risk factors may mask the correlation between Mg status and depression. This finding is compatible with that of Derom et al. demonstrating that the increase of Mg intake (in 12939 subjects with the mean age of $37.6 \pm 11.7$ years) could not significantly decrease the risk of developing depression [1]. Eby et al. also stated no significant correlations between blood and CSF Mg levels with depression [36]. In contrast to our results, Tarleton by a randomized clinical trial showed that administration of 248 mg of daily magnesium supplement for 2 weeks could improve mild to moderate depression symptoms in adults [37]. The results of another study showed that $500 \mathrm{mg}$ daily $\mathrm{Mg}$ supplementation for 8 weeks could improve depression scores [38]. We could not find similar investigations to compare our results and these differences between the results may relate to diversities in the study designs and included participants with different demographic and clinical characteristics. 
Although all participants with the renal disease showed high levels of intracellular $\mathrm{Mg}$, the results showed that there were not any significant correlations between different diseases and intracellular $\mathrm{Mg}$ status. Previous studies have shown conflicting data on serum levels of magnesium in renal disease. Ford et al. revealed that older adults expose to the danger of Mg deficiency because of low absorption and high excretion of $\mathrm{Mg}$ in the kidney [39]. Mountokalakis showed a toxic serum Mg concentration in end-stage renal disease patients because of limited kidney ability for Mg excretion [40]. The other study indicated that chronic kidney disease by impairing kidney function may cause disturbance in the handling of Mg and result in either hypo or hypermagnesemia [41].

Additionally, our results showed that none of the different factors like dental health status, sunlight exposure, nutritional status, the satisfaction of NH's staff, and food quality could significantly alter intracellular Mg levels. It is supposed that cytosolic Mg levels are tightly controlled by hormonal, metabolic, and extra/intra cell membrane transport mechanisms through the expense of extracellular Mg levels [42, 44]. This explanation may demonstrate why we could not observe significant differences between our participants during such a short study period.

In the present study, we wanted to attract special attention to elderly people who are living in the nursing home as a vulnerable group with an eye on their mental and non-mental complications. There are very few studies about magnesium and depression. Moreover, while serum magnesium determination is a simple and widely used approach evaluating Mg status, the strength of the present study was assessing intracellular Mg as a reliable method. It was speculated that magnesium deficiency may contribute to the aging process and age-related problems. Also, the roles of nutritional diet and stress on Mg deficiency have been shown. Our results could not delineate these correlations with intracellular Mg levels. Herein, these diverse findings indicate the need for further investigation with a larger elderly population.

It should be also mentioned that our study had several limitations. We did not consider the duration of residency of participants in nursing homes. The levels of serum Mg were not measured among the study population that that could provide beneficial data for comparison of intra and extracellular Mg concentration. We did not gather data regarding participants' antidepressants consumption; however, these drugs may affect Mg levels. Our sample size was also small because of few non-cooperative participants as well as limited financial and human recourses.

\section{Conclusion}

The results of the present study showed notable prevalence rates of depression and malnutrition among the elderly nursing home residents. It was also found that the relationships between intracellular Mg levels with depression or other chronic diseases including diabetes, hypertension, heart and renal diseases were not significant. Further studies are needed to determine the major factors related to these preventable psychological and nutritional disorders among elderly $\mathrm{NH}$ residents.

\section{Compliance with ethical standards}

\section{Acknowledgments}

This research has been supported by a grant (No: 88-1-27-4656) from Tehran University of Medical Sciences, the National Health Research Association, and the National Institute of Health Research. We would like to acknowledge their kind support.

\section{Disclosure of conflict of interest}

The authors declare no conflict of interest.

\section{Statement of informed consent}

Informed consent was obtained from all individual participants included in the study.

\section{References}

[1] Derom M-L, Martínez-González MA, Sayón-Orea MdC, Bes-Rastrollo M, Beunza JJ, Sánchez-Villegas A. Magnesium intake is not related to depression risk in Spanish university graduates. The Journal of nutrition. 2012; 142(6): 1053-9. 
[2] Tam M, Gomez S, Gonzalez-Gross M, Marcos A. Possible roles of magnesium on the immune system. European journal of clinical nutrition. 2003; 57(10): 1193-7.

[3] Champagne CM. Magnesium in hypertension, cardiovascular disease, metabolic syndrome, and other conditions: a review. Nutrition in Clinical Practice. 2008; 23(2): 142-51.

[4] DiNicolantonio JJ, O’Keefe JH, Wilson W. Subclinical magnesium deficiency: a principal driver of cardiovascular disease and a public health crisis. Open heart. 2018; 5(1): e000668.

[5] Eby III GA, Eby KL. Magnesium for treatment-resistant depression: a review and hypothesis. Medical hypotheses. 2010; 74(4): 649-60.

[6] Barbagallo M, Belvedere M, Dominguez LJ. Magnesium homeostasis and aging. Magnesium Research. 2009; 22(4): 235-46.

[7] Serefko A, Szopa A, Wlaź P, Nowak G, Radziwoń-Zaleska M, Skalski M, et al. Magnesium in depression. Pharmacological Reports. 2013; 65(3): 547-54.

[8] Buysse DJ, Angst J, Gamma A, Ajdacic V, Eich D, Rössler W. Prevalence, course, and comorbidity of insomnia and depression in young adults. Sleep. 2008; 31(4): 473-80.

[9] Nazemi L, Skoog I, Karlsson I, Hosseini S, Hosseini M, Hosseinzadeh MJ, et al. Depression, prevalence and some risk factors in elderly nursing homes in Tehran, Iran. Iranian journal of public health. 2013; 42(6): 559.

[10] Djernes JK. Prevalence and predictors of depression in populations of elderly: a review. Acta Psychiatrica Scandinavica. 2006; 113(5): 372-87.

[11] Chollet D, Franken P, Raffin Y, Henrotte J-G, Widmer J, Malafosse A, et al. Magnesium involvement in sleep: genetic and nutritional models. Behavior genetics. 2001; 31(5): 413-25.

[12] Andrasi E, Igaz S, Molnár Z, Mako S. Disturbances of magnesium concentrations in various brain areas in Alzheimer's disease. Magnesium research. 2000; 13(3): 189-96.

[13] Jacka FN, Maes M, Pasco JA, Williams LJ, Berk M. Nutrient intakes and the common mental disorders in women. Journal of affective disorders. 2012; 141(1): 79-85.

[14] Flink EB. Nutritional aspects of magnesium metabolism. Western Journal of Medicine. 1980; 133(4): 304.

[15] Elin RJ. Magnesium: the fifth but forgotten electrolyte. American journal of clinical pathology. 1994; 102(5): 61622.

[16] Sauberlich HE. Laboratory tests for the assessment of nutritional status: Routledge. 2018.

[17] D'ATH P, Katona P, Mullan E, Evans S, KatonaC. Screening, detection and management of depression in elderly primary care attenders. I: The acceptability and performance of the 15 item Geriatric Depression Scale (GDS15) and the development of short versions. Family practice. 1994; 11(3): 260-6.

[18] Norris JT, Gallagher D, Wilson A, Winograd CH. Assessment of depression in geriatric medical outpatients: The validity of two screening measures. Journal of the American Geriatrics Society. 1987; 35(11): 989-95.

[19] Hackett ML, Yapa C, Parag V, Anderson CS. Frequency of depression after stroke: a systematic review of observational studies. Stroke. 2005; 36(6): 1330-40.

[20] Almeida OP. Prevention of depression in older age. Maturitas. 2014; 79(2): 136-41.

[21] Basun H, Fratiglioni L, Winblad B. Cobalamin levels are not reduced in Alzheimer's disease: results from a population-based study. Journal of the American Geriatrics Society. 1994; 42(2): 132-6.

[22] Lindholm LH, Ibsen H, Dahlöf B, Devereux RB, Beevers G, de Faire U, et al. Cardiovascular morbidity and mortality in patients with diabetes in the Losartan Intervention For Endpoint reduction in hypertension study (LIFE): a randomised trial against atenolol. The Lancet. 2002; 359(9311): 1004-10.

[23] Gallacher R, Browning M, Fraser C, Wilkinson S, MacLennan W. A method for simultaneously estimating plasma, erythrocyte, and leukocyte sodium, potassium, and magnesium: reference values and considerations from biological variation data. Clinical chemistry. 1987; 33(8): 1326-30.

[24] Imran A, Azidah A, Asrenee A, Rosediani M. Prevalence of depression and its associated factors among elderly patients in outpatient clinic of Universiti Sains Malaysia Hospital. The Medical Journal of Malaysia. 2009; 64(2): 134-9. 
[25] Cole MG, Dendukuri N. Risk factors for depression among elderlycommunity subjects: a systematic review and meta-analysis. American Journal of Psychiatry. 2003; 160(6): 1147-56.

[26] Eby GA, Eby KL. Rapid recovery from major depression using magnesium treatment. Medical hypotheses. 2006; 67(2): 362-70.

[27] Gilbride JA, Amella EJ, Breines EB, Mariano C, Mezey M. Nutrition and health status assessment of communityresiding elderly in New York City: a pilot study. Journal of the American Dietetic Association. 1998; 98(5): 5548.

[28] Lyly N, Ingmar S, Ingvar K, Saeed H, MostafaH, Mohammad Javad H, et al. Depression, prevalence and some risk factors in elderly nursing homes in tehran, iran. Iranian Journal of Public Health. 1970; 42(6).

[29] Diana S, Masoumeh P, Ali Hasanpour D, Kourosh S, Abbas M. Prevalence of Depression among Iranian Elderly: Systematic Review and Meta-Analysis. Iranian Journal of Psychiatry. 2018; 13(1).

[30] Jafari H, Ghasemi-Semeskandeh D, Goudarzian AH, Heidari T, Jafari-Koulaee A. Depression in the Iranian elderly: a systematic review and meta-analysis. Journal of aging research. 2021; 2021.

[31] Isfahani P, Afshin M, Mohammadi F, Arefnezhad M. Prevalence of depression among Iranian elderly: A Systematic review and Meta-analysis. J Gerontol. 2021; 5(3): 66-77.

[32] Tang M, Wang S-H, Li H-L, Chen H, Sun X-Y, BianW-W, et al. Mental health status and quality of life in elderly patients with coronary heart disease. PeerJ. 2021; 9: e10903.

[33] Ai AL, Carretta H. Depression in patients with heart diseases: Gender differences and association of comorbidities, optimism, and spiritual struggle. International Journal of Behavioral Medicine. 2021; 28(3): 38292.

[34] Lyly N, Ingmar S, Ingvar K, Saeed H, Mohammad Reza M, Mostafa H, et al. Malnutrition, Prevalence and Relation to Some Risk Factors among Elderly Residents of Nursing Homes in Tehran, Iran. Iranian Journal of Public Health. $1970 ; 44(2)$.

[35] Madeira T, Severo M, Correia D, Lopes C, Clara JG. Nutritional intake and malnutrition in institutionalised and non-institutionalised older adults. British Journal of Nutrition. 2021: 1-11.

[36] Eby GA, Eby KL. Magnesium for treatment-resistant depression: A review and hypothesis. Medical Hypotheses. 2010; 74(4): 649-60.

[37] Tarleton EK, Littenberg B, MacLean CD, Kennedy AG, Daley C. Role of magnesium supplementation in the treatmentof depression: A randomized clinical trial. PloS one. 2017; 12(6): e0180067.

[38] Afsharfar M, Shahraki M, Shakiba M, Asbaghi O, Dashipour A. The effects of magnesium supplementation on serum level of brain derived neurotrophic factor (BDNF) and depression status in patients with depression. Clinical nutrition ESPEN. 2021; 42: 381-6.

[39] Ford ES, Mokdad AH. Dietary magnesium intake in a national sample of US adults. The Journal of nutrition. 2003; 133(9): 2879-82.

[40] Mountokalakis T. Magnesium metabolism in chronic renal failure. Magnesium research. 1990; 3(2): $121-7$.

[41] Rodelo-Haad C, de Mier MVP-R, Díaz-Tocados JM, Martin-Malo A, Santamaria R, Muñoz-Castañeda JR, et al. The role of disturbed $\mathrm{Mg}$ homeostasis in chronic kidney disease comorbidities. Frontiers inCell and Developmental Biology. 2020; 8.

[42] Quamme GA. Magnesium homeostasis and renal magnesium handling. Mineral and electrolyte metabolism. 1993; 19(4-5): 218-25.

[43] Romani AM. Cellular magnesium homeostasis. Archives of biochemistry and biophysics. 2011; 512(1): 1-23.

[44] Romani AMP. Intracellular magnesium homeostasis. In: Vink R, Nechifor M, editors. Magnesium in the Central Nervous System [Internet]. Adelaide (AU): University of Adelaide Press. 2011. 